\title{
Study on the Electro-Osmosis Characteristics of Soft Clay from Taizhou with Various Saline Solutions
}

\author{
Yang Shen $\mathbb{D}$, ${ }^{1,2}$ Wen Shi $\mathbb{D},{ }^{1,2}$ Shaoyu Li $\mathbb{D},,^{1,2}$ Long Yang $\mathbb{D}^{1,2}$ Jianting Feng $\mathbb{D},{ }^{1,2}$ \\ and Mingjun Gao $\mathbb{1}^{1,2}$ \\ ${ }^{1}$ Key Laboratory of Geomechanics and Embankment Engineering of Ministry of Education, Hohai University, \\ Nanjing 210098, China \\ ${ }^{2}$ Jiangsu Research Center for Geotechnical Engineering Technology, Hohai University, Nanjing 210098, China
}

Correspondence should be addressed to Wen Shi; njsw95@163.com

Received 27 February 2020; Revised 28 July 2020; Accepted 28 August 2020; Published 15 September 2020

Academic Editor: Chunshun Zhang

Copyright (c) 2020 Yang Shen et al. This is an open access article distributed under the Creative Commons Attribution License, which permits unrestricted use, distribution, and reproduction in any medium, provided the original work is properly cited.

Chemical electro-osmosis with an injected saline solution can be described as an efficient method for adjusting the soil microstructure and improving soil conductivity, and the effect of electro-osmotic consolidation on soft foundations can also be improved by this novel technology in regard to foundation treatment. To better study the electro-osmotic characteristics of soft clay from Taizhou with different grouting solutions, a series of chemical electro-osmotic experiments concerning the injection of $\mathrm{CaCl}_{2}, \mathrm{MgCl}_{2}, \mathrm{NaCl}, \mathrm{KCl}$, and deionized water were conducted in the laboratory based on custom test devices. The actual treatment effects of these experiments were compared by monitoring the drainage, current, voltage, elemental mass fractions in the soil, and soil structure. The chemical electro-osmotic method was further studied from a theoretical perspective based on the inherent link between the macro- and microlevel indexes. The results of the model test indicated that the crystal structure of the soil changed from an initial flocculated structure to a granular or laminated structure with the injection of $\mathrm{CaCl}_{2}$ and $\mathrm{MgCl}_{2}$ saline. $\mathrm{Na}^{+}$was hereby replaced by multicharged ions, which served as the key factor that affected both the drainage efficiency and conductivity of the electro-osmotic process. Moreover, a novel one-dimensional electro-osmotic consolidation equation was introduced that considered variations in the electroosmotic permeability coefficient, which better illustrated how the excess pore water pressure was deduced when compared with Esrig's consolidation equation. Furthermore, the results of this experiment may be adopted as a reference or as evidence for the subsequent promotion and application of the electro-osmosis method.

\section{Introduction}

Electro-osmotic reinforcement has considerable advantages over other treatments of soil with high water content, high compressibility, low penetrability, low shear strength, and high liquid limit [1]. Currently, this technology has not been widely applied in practical engineering procedures because of its low efficiency and excessive energy consumption. To improve electro-osmotic techniques, many studies on the construction techniques of the electro-osmotic method [2-4] have been continuously conducted, and the feasibility of combinations of electro-osmosis reinforcement technology and other foundation reinforcement technologies has also been continuously explored.
Chemical electro-osmosis reinforcement can be regarded as the most typical method that combines chemical grouting and electro-osmosis. The expected effect of directional grouting can be effectively achieved by this method under an external electric field. Moreover, the defects of a single electro-osmotic method can also be improved to some extent, which can be reflected by the improvement in the uniform reinforcement effect and the decrease in the reinforcement time. At present, a series of studies have been carried out on the issue of salinity, types of saline, and injection time of saline. Laursen et al. [5] conducted a comparative test between bentonite and natural clay and found that the electro-osmotic permeability coefficient might be related to salinity. Ozkan et al. [6] studied the 
methods of chemical electro-osmosis to strengthen kaolinite by the injection of phosphate and aluminum ions. An average shear strength increase of $500 \%-600 \%$ was detected in the experiments. Lefebvre and Burnotte [7] also found that the injection of saline was capable of increasing the soil conductivity at the soil-electrode interface, and the effective voltage for the transfer of saline to soil was doubled; thus, the performance of electro-osmotic consolidation was also improved. Burnotte et al. [8] and others applied chemical solutions to treat the anode, and the total duration of electroosmosis was set to 48 days. It was detected that the efficiency 32 days before electro-osmosis could be very high, and the settlement reached $10 \%$ of the thickness of the treated soil layer, while the sedimentation of the body was measured as $2 \%$ in the following 16 days. Mohamedelhassan and Shang [9] adopted solutions of $15 \% \quad \mathrm{CaCl}_{2}$ and $10 \%$ $\mathrm{Al}_{2}\left(\mathrm{SO}_{4}\right)_{3} \cdot 18 \mathrm{H}_{2} \mathrm{O}$ and found that the reinforcement of soft soil was enhanced after an electro-osmosis treatment. Ou et al. [10] released in his paper that the effect of electroosmosis on silty clay was enhanced and the treatment time was also reduced by injecting calcium chloride saline during the electro-osmosis process, although the effect of the treatment was restricted to the anodic region.

The test results shown above all indicate that the increased content of cations by injecting saline can be beneficial to the transport of hydrated cations to the cathode, while relatively less research has been conducted to study the differences between the type of grouting solutions and the microscopic studies on the law of ion migration. During the electro-osmosis process, a series of physical and chemical interactions occurred, and the electrochemical phenomena involved in the electro-osmotic process were extremely complicated, thereby making the effect of soft soil reinforcement unstable. Therefore, some fundamental problems, such as the microscopic mechanism and the design parameters of the chemical electro-osmotic method, must be appropriately studied before practical application.

Taizhou soft clay was introduced as the research object in this paper to thoroughly explore its electro-osmotic characteristics with various saline solutions. Electro-osmotic experiments were conducted with five solutions, namely, $\mathrm{CaCl}_{2}, \mathrm{MgCl}_{2}, \mathrm{NaCl}, \mathrm{KCl}$, and deionized water. The results were later analyzed from macroscopic and microscopic perspectives, and the differences in the reinforcement effect of different saline solutions at the same concentration could be explored. Furthermore, a reasonable explanation for the macroscopic phenomena was explored when combined with the microstructure and element analysis. A novel one-dimensional electro-osmotic consolidation equation was also later deduced to provide references and evidence for the application of electro-osmotic methods in the treatment of soft clay foundations in various regions.

\section{Materials and Methods}

2.1. Experimental Materials. The soil samples used in the experiment could be classified as typical mucky, silty clay and were taken from a construction site that employs vacuum preloading in Taizhou. The geotechnical properties and the mineral composition of the soil samples are recorded in Table 1.

Considering the actual engineering situation, the horizontal electro-osmotic test model simply consisted of a sample slot and a collection tank (see Figure 1). The internal dimensions of the model were $250 \mathrm{~mm} \times 200 \mathrm{~mm} \times 200 \mathrm{~mm}$ $(L \times H \times W)$. A small hole was positioned at the bottom of the collecting tank for collecting water discharged during the electro-osmosis process. Other major test devices included a stabilized DC power supply IT6863A, with a maximum output voltage of $72 \mathrm{~V}$ and a maximum output power of $108 \mathrm{~W}$. Voltage measuring probes were equidistantly arranged in the model slot combined with a multimeter to measure the effective voltage of the soil.

When compared with traditional metal electrodes, the electrokinetic geosynthetic (EKG) electrode (see Figure 2) applied in this experiment presents sound electrical conductivity and corrosion resistance and could avoid the metal cations induced by the metal electrodes $[11,12]$. The EKG is generally composed of a substrate, a geomembrane, and numerous wires. The substrate is made of conductive plastic plates, and both sides of the substrate are covered with grooves to facilitate drainage. Two copper wires connected to the power supply are embedded inside the substrate. To prevent the fine particle clay from blocking the drainage channel of the electrode plate during the experiment, the EKG electrode plate was wrapped with a dense filter membrane in advance, and its bottom was sealed.

2.2. Design of the Experiment. Five subexperiments were performed, and the EKG electrode was utilized as the basic material. To avoid the effects of differences in grouting location on the soil treatment and mainly focus on the effect of the various saline on the electro-osmosis treatment, a method of mixing [13] was hereby introduced for experimental research instead of injection grouting. The laboratory experiments were conducted in five solutions, including calcium chloride, magnesium chloride, sodium chloride, and potassium chloride solutions and deionized water, where the initial water content remained consistent. Considering the research of $\mathrm{Li}$ and Gong [13] on the optimal soil salinity of the electro-osmotic method, the mass of solute is determined to $0.25 \%$ of the dry soil by weight. According to the results of the preliminary test, the applied voltage was set to $15 \mathrm{~V}$, and the experimental time was set to $48 \mathrm{~h}$. The physical and mechanical properties of the soil samples are summarized in Table 2.

The specific procedures can be described as follows: (1) certain amounts of dried soil were crushed and passed through a sieve with a $0.075 \mathrm{~mm}$ opening. The mass of required water was calculated according to the assumption that the initial water content of the soil was $45 \%$. (2) A total of $35 \mathrm{~g}$ of salt solution and $1000 \mathrm{~g}$ of deionized water were measured and mixed before taking $400 \mathrm{~g}$ of saline for later application. (3) After that, the soil and water were thoroughly mixed using an electric mixer to generate a remolded soil sample. The remolded soil was kept stationary for $24 \mathrm{~h}$, after which its water content was measured. (4) The EKG 
TABLE 1: Summary of the geotechnical properties and mineral composition.

\begin{tabular}{lcccccc}
\hline Specific gravity & Liquid limit (\%) & Plastic limit (\%) & Plasticity index & \multicolumn{2}{c}{ Soil particle composition (\%) } \\
Sand & & Silt & Clay \\
\hline 2.71 & 39 & 21 & 18 & 0 & 79 \\
\hline
\end{tabular}

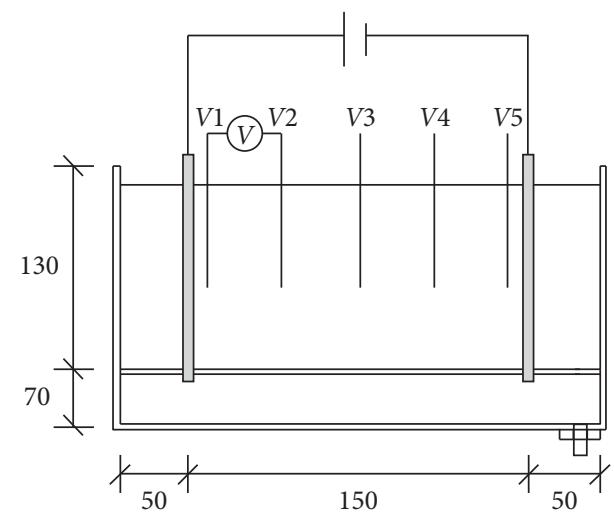

FIGURE 1: Elevation view of the model.

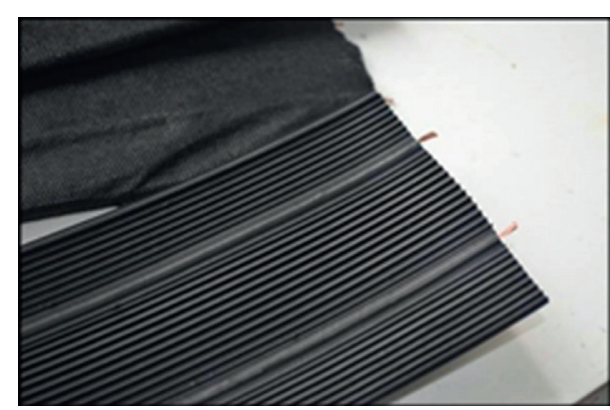

FIGURE 2: Photograph of the tabular EKG.

TABLE 2: Basic parameters of the laboratory experiments.

\begin{tabular}{lccc}
\hline $\begin{array}{l}\text { Test } \\
\text { numbers }\end{array}$ & Saline & $\begin{array}{c}\text { Test time } \\
(\mathrm{h})\end{array}$ & $\begin{array}{c}\text { Initial water content } \\
(\%)\end{array}$ \\
\hline $\mathrm{T} 1$ & $\begin{array}{c}\text { Deionized } \\
\text { water }\end{array}$ & 48 & 53.3 \\
$\mathrm{~T} 2$ & $\mathrm{KCl}$ solution & 48 & 52.1 \\
$\mathrm{~T} 3$ & $\mathrm{MgCl}_{2}$ solution & 48 & 54.6 \\
$\mathrm{~T} 4$ & $\mathrm{NaCl}^{2}$ solution & 48 & 53.1 \\
$\mathrm{~T} 5$ & $\mathrm{CaCl}_{2}$ solution & 48 & 53.6 \\
\hline
\end{tabular}

electrode was placed at the corresponding position in the sample slot, which also served as both the cathode and the anode in the concrete experiment. (5) The soil was applied in four layers to achieve a denser state by means of packing. A measuring cylinder was placed under the small hole of the collection tank to measure the weight of water discharged in the electro-osmotic process. (6) Voltage probes were arranged in equal distances between the cathode and anode. (7) The wires, power supply, and electrodes were connected, and the output voltage of the power supply was adjusted to $15 \mathrm{~V}$; at this point, the circuit was constructed. (8) The current readings were recorded every half hour. Additionally, soil voltages and liquid volumes were measured. (9)
After reacting for $45 \mathrm{~h}$, the test was stopped, and the power supply was disconnected. (10) Soil samples near the vicinity of the electrodes were selected, and portions of the samples were freeze-dried for scanning electron microscopy (SEM). The other sample portions were dried as well. Finally, the soil was crushed by a mortar and sifted through a $0.075 \mathrm{~mm}$ sieve. The chemical composition of the soil was then examined by X-ray fluorescence (XRF) spectrometry.

\section{Results and Discussion}

\subsection{Macrolevel}

3.1.1. Discharge of Water. The variations in the volume of drained water over time for all experiments are shown in Figure 3. T1-T5 was generally divided into three main stages of electro-osmosis drainage: the linear growth stage (Stage 1), nonlinear growth stage (Stage 2), and stationary stage (Stage 3). In the initial stage of electro-osmosis, the high water content resulted in the soil particles being in a suspended state, which was mainly associated with liquid phase conduction. The drainage rate was fast, and the electro-osmotic drainage volume increased in an approximately linear manner. As the pore water was continuously discharged, the electro-osmosis solid-liquid conduction interactions were presented as the dominant reaction, and the drainage rate gradually decreased in Stage 2 of the experiment (Figure 4). In Stage 3, the soil became unsaturated, and the water film of the soil particles was thin and discontinuous; consequently, the conductivity was mainly determined by the thickness of the electric double layer [14]. Additionally, electro-osmosis was considered to be finished once the drainage rate was less than $1 \mathrm{ml} / \mathrm{h}$.

In addition, it is also shown in Figure 3 that there is a different drainage volume with each group. Specifically, larger drainage volumes were found with the T3 $\left(\mathrm{Mg}^{2+}\right)$ and T5 $\left(\mathrm{Ca}^{2+}\right)$ groups, which were measured as 290 and $360 \mathrm{ml}$, respectively. In contrast, the drainage volumes of the $\mathrm{T} 1$ (no solute) and T2 $\left(\mathrm{K}^{+}\right)$groups were measured as $160 \mathrm{ml}$ and $150 \mathrm{ml}$, respectively. The abovementioned comparison showed that the multicharged saline solutions had relatively higher drainage capacity values than the drainage capacity values of the monovalent saline solutions, which was attributed to the higher charge brought by the multicharged ions. Furthermore, multicharged ions were capable of making the water film on the clay surface thinner, which further improved the conductivity capacity of the soil. This improved conductivity capacity resulted in an increase in the electro-osmotic permeability coefficient of the soil and an increase in the drainage effect. 


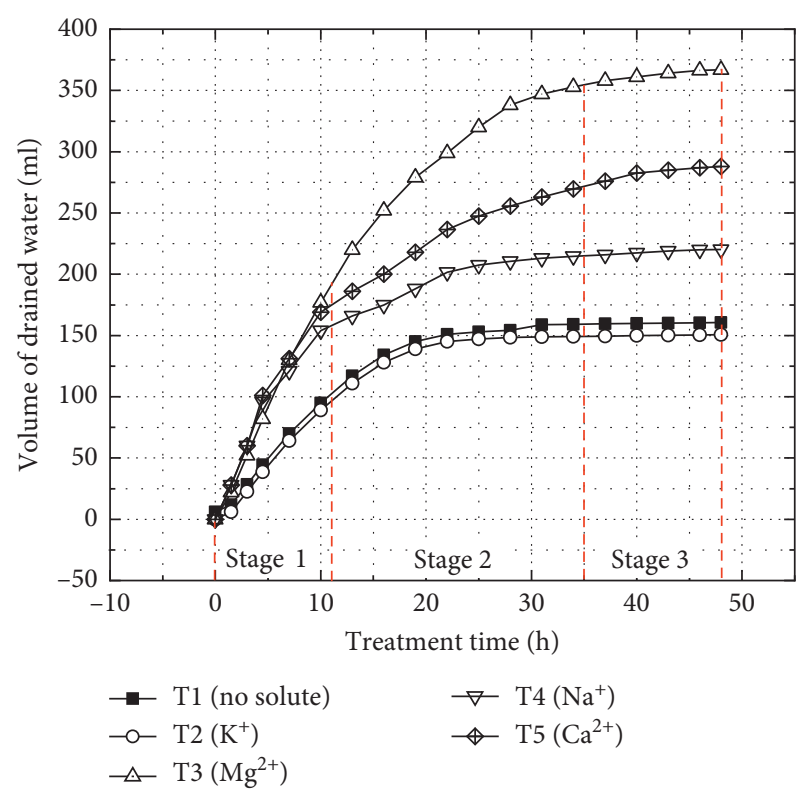

FIgURE 3: Volume of drainage variations over treatment time.

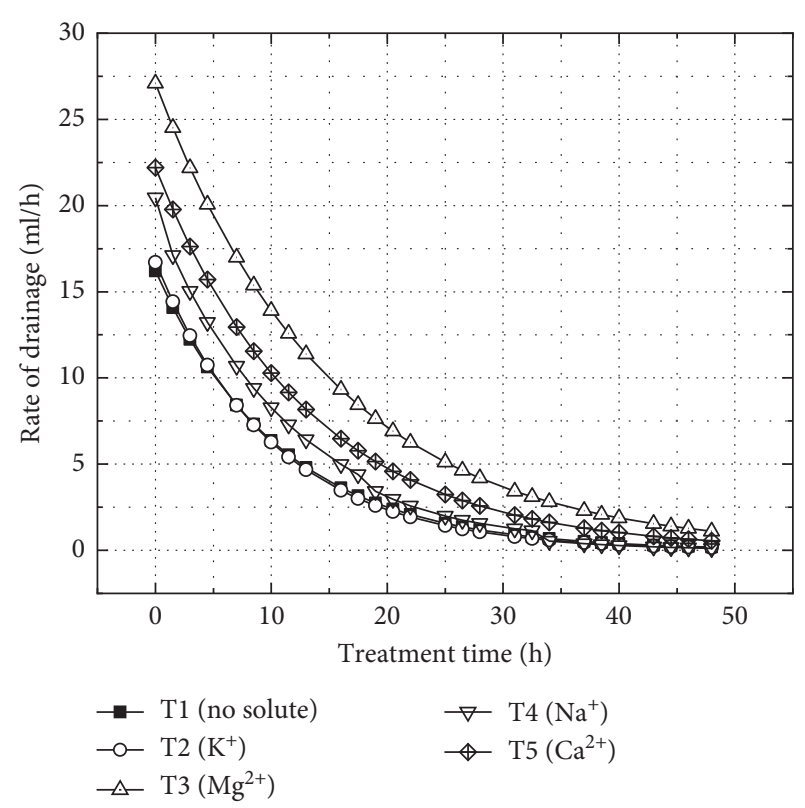

FIGURE 4: Drainage rate variations over treatment time.

3.1.2. Effective Electric Voltage. The effective electric voltage refers to the actual voltage obtained at both ends of the soil, while considering the influence of factors such as the interface resistance between the soil and electrode. As illustrated in Figure 5, the effective electric voltage of each experiment decreased exponentially over time and tended to be stable at the end of the experiment. When compared with the T1 (no solute) group, injected ions entered the soil under the force of an external electric field, which increased the conductivity of the soil. As the reaction proceeded, the pore water of the soil was gradually discharged, and a soil-bound water film appeared to be discontinuous. The electro-

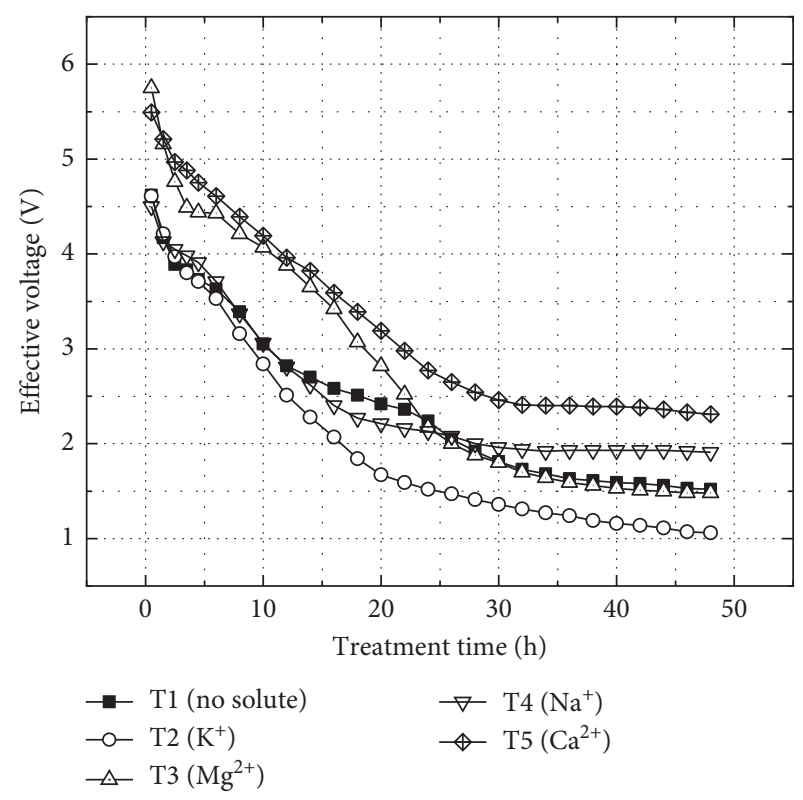

FIgURE 5: Effective voltage variations over treatment time.

osmotic permeability coefficient decreased as the soil resistance increased, which led to a decrease in the effective voltage. At the beginning of the experiment, the effective voltages of T3 $\left(\mathrm{Mg}^{2+}\right)$ and T5 $\left(\mathrm{Ca}^{2+}\right)$ reached $36 \%$ and $38 \%$ of the applied voltage, respectively, whereas those of the other groups reached approximately $30 \%$ of the total amount. These results showed that a large interfacial resistance and obvious voltage loss could be detected when the applied voltage passed through the interface between the electrode and soil mass.

Furthermore, multicharged ions in the middle-later period of this experiment still presented a high voltage level, which is mainly caused by the fact that the soil was mainly dominated by ionic conduction at the solid-liquid interface after the discharge of pore water, and the exchange of $\mathrm{Ca}^{2+}$ and $\mathrm{Mg}^{2+}$ lowered the thickness of the electric double layer. As the pore water was discharged, the conductivity of pore water decreased. At that time, ionic conduction played a leading role in the reaction, and the advantages of multicharged ions could be observed.

3.1.3. Current Intensity. The current variations in the laboratory experiments are illustrated in Figure 6. The pore water of the soil was continuously discharged as the electroosmosis reaction continued, and the soil water film then became discontinuous and led to an increase in soil resistance. Moreover, cracks were detected at the interface between the electrode material and soil; at these points, the contact surface resistance was increased, and consequently, the electro-osmotic permeability coefficient decreased. Thus, the current intensity decayed exponentially and tended to be stable in the end. The depletion of ions due to electric current migration served as the reason for the final current intensity of different saline samples tending to be consistent. Initially, the initial current of the T3 $\left(\mathrm{Mg}^{2+}\right)$ and $\mathrm{T} 5\left(\mathrm{Ca}^{2+}\right)$ groups 


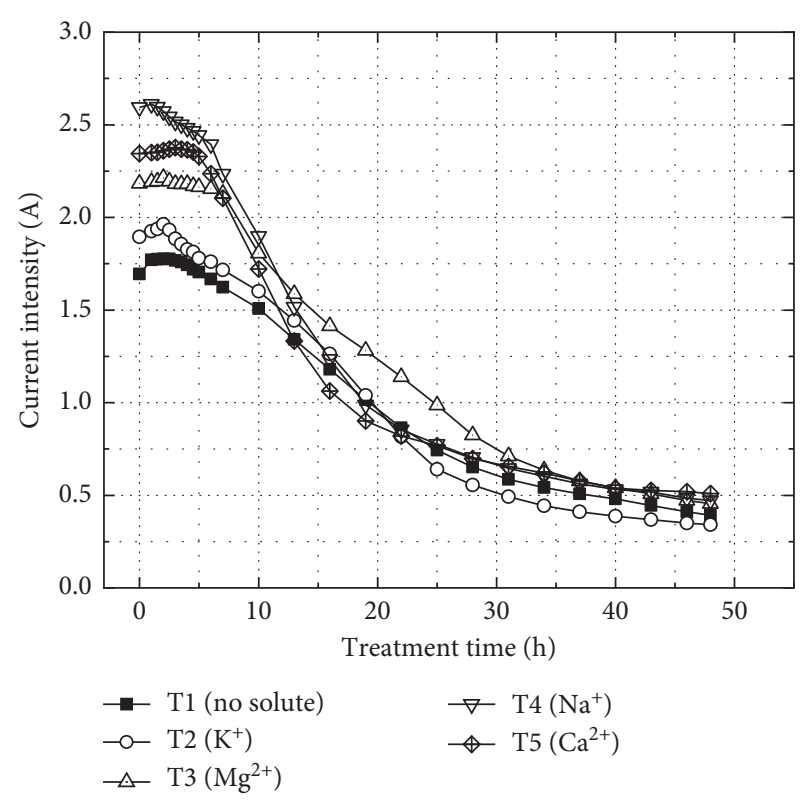

FIgURE 6: Current intensity variations over treatment time.

reached 2.4 A, and the peak current of $\mathrm{T} 1$ (no solute) and $\mathrm{T} 2$ $\left(\mathrm{K}^{+}\right)$did not even exceed $2 \mathrm{~A}$. These results explained the reason for the better drainage effect of the $\mathrm{T} 3\left(\mathrm{Mg}^{2+}\right)$ and $\mathrm{T} 5$ $\left(\mathrm{Ca}^{2+}\right)$ groups.

3.1.4. Electro-Osmotic Permeability Coefficient. The definition of the electro-osmotic permeability coefficient is determined by the hydraulic permeability coefficient, which refers to the flow velocity of seepage water under a unit voltage gradient. It characterizes the level of difficulty of a fluid passing through a pore skeleton under an electric field [15]. The expression of the electro-osmotic permeability coefficient can be written as follows:

$$
k_{e}=\frac{v}{i_{e}}=\frac{Q}{A} \cdot \frac{\partial L}{\partial \varphi}
$$

where $v$ is the flow rate of electro-osmosis, $i_{e}$ is the voltage gradient, $Q$ is the flow of electro-osmosis, $A$ is the area of the electro-osmotic flow section, $L$ is the length of the seepage path, and $\varphi$ is the applied voltage.

Considering the existence of the soil-electrode interfacial resistance as well as the occurrence of cracks near the electrode, there a considerable loss of applied voltage occurred; in this paper, the measured effective voltage was taken as the calculated value of $\varphi$. According to the measured current and effective voltage at both ends of the soil, as shown in Figure 7, the electro-osmotic permeability coefficient of each grouting solution was calculated. As the ionic valence of the grouting solution increased, it was evident that the electro-osmotic permeability coefficient of the soil increased to some extent after solution grouting; among the various groups, the increase in the electro-osmotic permeability coefficient of the $\mathrm{T} 3\left(\mathrm{Mg}^{2+}\right)$ group was the most significant. This result was consistent with the change rule of effective voltage, which also verified that a high valence ion

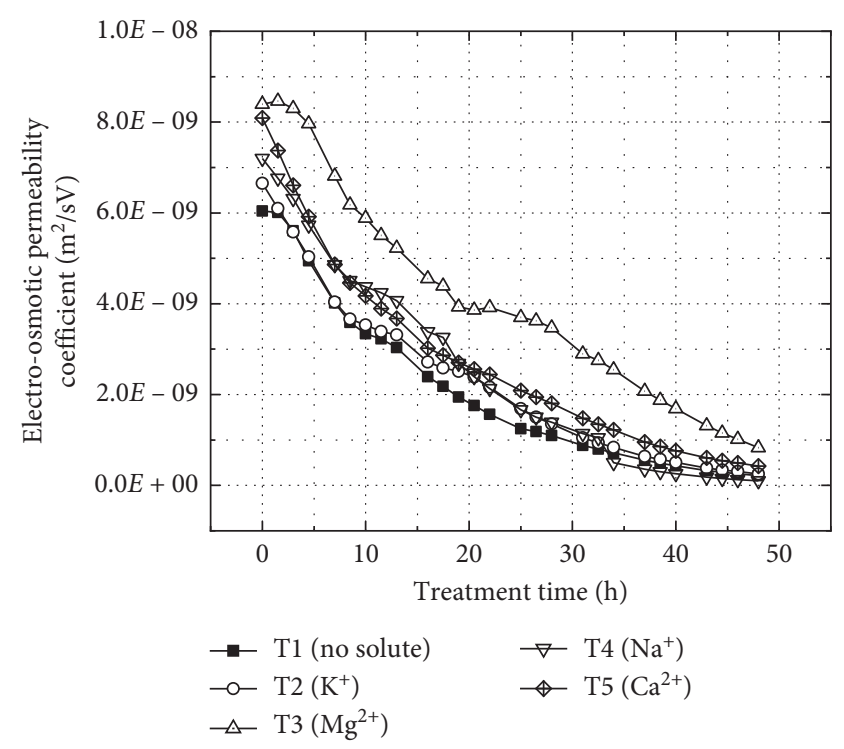

FIgURE 7: Coefficient of the electro-osmotic permeability variations over treatment time.

solution was conducive to the electro-osmosis process. In addition, the electro-osmotic permeability coefficient changed according to the treatment time, which more or less reflected the irrationality of the existing electro-osmosis consolidation theory in that the electro-osmotic permeability coefficient was constant. Therefore, in the second half of this paper, based on the existing consolidation equation, a one-dimensional consolidation equation of the electro-osmotic permeability coefficient is deduced, which is supposed to more accurately conform to the actual situation.

3.2. Microlevel. Scholars around the world have conducted numerous studies on the electro-osmotic process; however, most of those investigations provided descriptions and data analysis only concerning the macrolevel. Thus, insufficient research has been performed from the microlevel perspective; consequently, the microscopic mechanism of electroosmosis is currently unclear. To further explore the microscopic effects and mechanism of the electro-osmotic process with different kinds of saline solution, the migration of ions in soil under the force of an electric field and the change in the soil structure were examined after the electroosmotic process. Based on these studies, reasonable explanations for the abovementioned macroscopic phenomenon were provided from a microscopic perspective. The results of the microlevel analysis are illustrated as follows.

3.2.1. Analysis of Soil Structure and Porosity. Soil near the anode was gathered and freeze-dried because the best electro-osmotic treatment effect can be achieved near the anode. Subsequently, the soil structure was studied using a QUANTA200 SEM instrument. Figure 8 illustrates the structure of Taizhou soft clay at the anode before and after electro-osmosis. Figure 8(a) presents the SEM image of the untreated soil. The basic skeleton of the soft clay was 


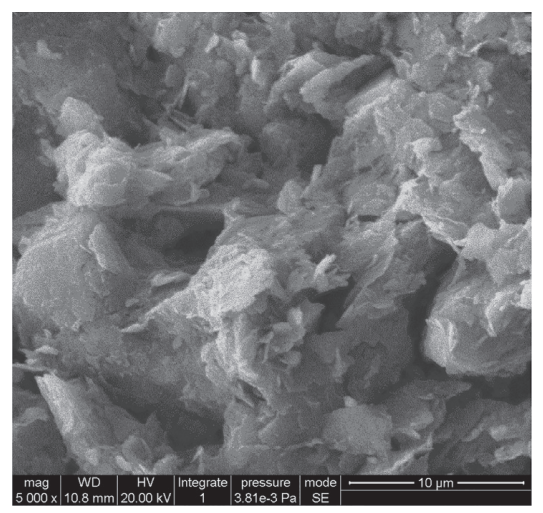

(a)

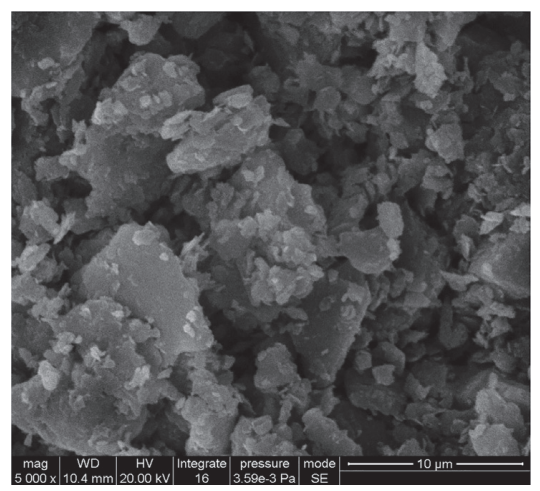

(d)

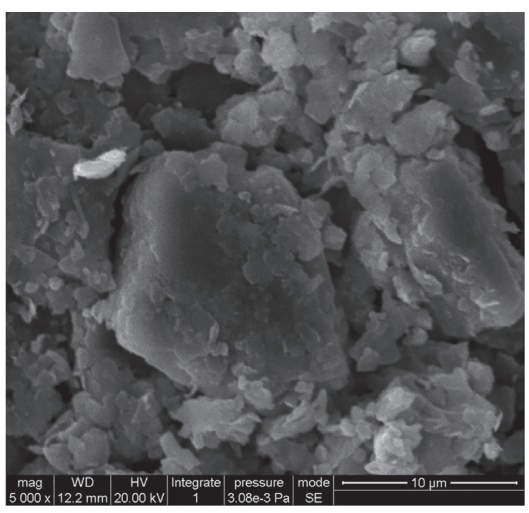

(b)

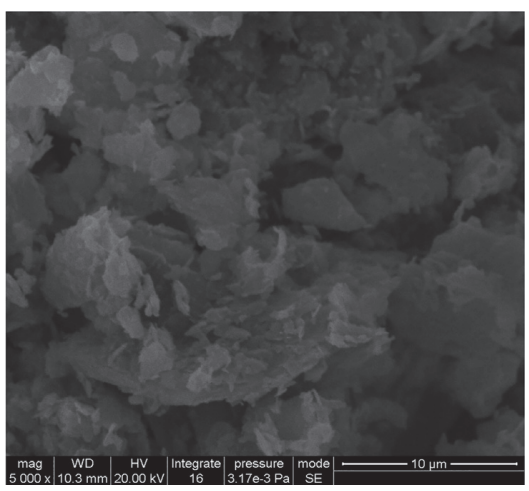

(e)

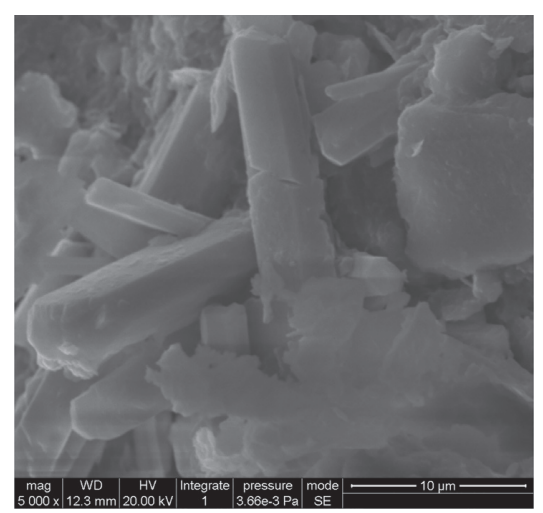

(c)

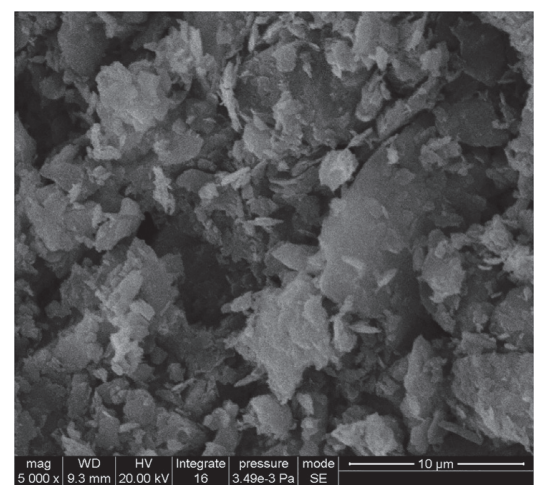

(f)

FiguRE 8: Scanning electron micrographs of the soil sample at the anode before and after the electro-osmosis process (5000x magnification). (a) Untreated soil. (b) $\mathrm{T} 1$ (no solute). (c) $\mathrm{T} 2\left(\mathrm{~K}^{+}\right)$. (d) $\mathrm{T} 3\left(\mathrm{Mg}^{2+}\right)$. (e) $\mathrm{T} 4\left(\mathrm{Na}^{+}\right)$. (f) $\mathrm{T} 5\left(\mathrm{Ca}^{2+}\right)$.

composed of clay aggregates, and the clay slices could be wavy or crumpled. The particles were mainly associated in the form of face-to-face and face-to-edge contacts. A flocculent structure was detected in the soft clay, which could be characterized by a loose structure and high porosity. This kind of structure explained the characteristics of soft clay from Taizhou: the low strength, high compressibility, and high flow denaturation. Figure 8(b) shows the control group of the processed soil samples (T1 (no solute)), which could be semiflocculated and tended to granulate. A relatively high water content could be found at the macrolevel. The rate of water content in the treated soil in the $\mathrm{T} 4\left(\mathrm{Na}^{+}\right)$group in Figure $8(\mathrm{e})$ was significantly reduced, and the characteristics of the soil particles were more obvious: a soft, wrinkled structure. The structure of soft clay gradually changed from a flocculent state to a granular state after the electro-osmotic treatments. The size of the soil particles in $\mathrm{T} 5\left(\mathrm{Ca}^{2+}\right)$ ranged from $2 \mu \mathrm{m}$ to $12 \mu \mathrm{m}$ according to Figure $8(\mathrm{f})$. When compared with the flocculated structure, the soil particles of the two structures mentioned above had relatively large interfacial areas, despite the observed structure being found to be more compact. Moreover, it could be found in the T3 $\left(\mathrm{Mg}^{2+}\right)$ group that there were obvious white attachments on the surface of the particles, which was caused by the cementation material generated by $\mathrm{Ca}^{2+}$. This kind of reaction not only filled the pores but strengthened the cementation between soil particles. It could also be found that the variation in grouting cations would cause some changes in the structure of the soil. With the progress of electro-osmosis, the substitution of cations occurred in the electrical double layer and between the clay lattices. Sodium ions could be substituted by multicharged ions, which led to changes in geotechnical properties such as the size of the particles, conductivity, coefficient of hydraulic permeability, and electro-osmotic permeability.

In addition, SEM images of soil samples allow not only changes in the soil structure to be qualitatively analyzed but also information and data concerning the arrangement of pores, particle size, and particle shape to be obtained. It can be hereby determined that the gray values of the pixels in the image represents a certain particle volume, and different gray values represent the distance between the soil particles and the light source. The lighter the color is, the taller the height in the image. Each pixel can be applied as a base to form a cuboid, which occupies a certain volume of space. The raised part is regarded as the sum of the volume of the soil particles, and the remaining space represents the sum of the pore volume [16].

Based on the above understanding, this paper applies the $3 \mathrm{D}$ visualization and $3 \mathrm{D}$ analysis module provided in the GIS software and combines it with the SEM images of the soil obtained from the test to process and quantitatively analyze the SEM images. The porosity of the soil was calculated by this kind of technique. To reduce the calculation 
error, the SEM image with a magnification of $1000 \mathrm{X}$ was selected for $3 \mathrm{D}$ processing in this section. Figure 9 illustrates the $3 \mathrm{D}$ visualizations of the soil samples. After the $3 \mathrm{D}$ visualization process, the actual shape of the particles and the distribution characteristics of the soil pores could be detected in a more intuitive way. The results of the porosity calculations are shown in Table 3 . The porosity of T3 $\left(\mathrm{Mg}^{2+}\right)$ and T5 $\left(\mathrm{Ca}^{2+}\right)$ after the electro-osmotic process decreased to approximately $25 \%$, and its treatment effect was much more significant than that of the monovalent ion group. The results were consistent with the macroscopic results mentioned above; T3 $\left(\mathrm{Mg}^{2+}\right)$ and T5 $\left(\mathrm{Ca}^{2+}\right)$ presented higher effective voltages, better drainage effects, and more ideal porosities than the monovalent ion groups and control.

3.2.2. Elemental Content Analysis of Soil. To explore the patterns of ion migration and the chemical reaction that occurs during the electro-osmosis process, the elemental content of the soil near the electrodes was also analyzed after the electro-osmosis treatment. Then, reasonable explanations for the abovementioned macroscopic phenomena were provided from a microscopic perspective.

The results are shown in Figure 10, where A and C represent the anode and the cathode, respectively. According to the ion exchange sequence proposed by Mitchell and Soga [17], the general order of exchangeability is $\mathrm{Na}^{+}<\mathrm{Li}^{+}<$ $\mathrm{K}^{+}<\mathrm{Rb}^{+}<\mathrm{Cs}^{+}<\mathrm{Mg}^{2+}<\mathrm{Ca}^{2+}<\mathrm{Ba}^{2+}<\mathrm{Cu}^{2+}<\mathrm{Al}^{3+}<\mathrm{Fe}^{3+}$. It can be seen from the figure that the exchangeability of $\mathrm{Ca}^{2+}$ and $\mathrm{Mg}^{2+}$ was greater than that of $\mathrm{K}^{+}$and $\mathrm{Na}^{+}$. It can also be found in the figure that the quantity of $\mathrm{Ca}^{2+}$ and $\mathrm{Mg}^{2+}$ at the anode decreased, which could be caused by the entry of the multicharged $\mathrm{Ca}^{2+}$ and $\mathrm{Mg}^{2+}$ ions into the soil, which replaced $\mathrm{Na}^{+}$in the electric double layer. Consequently, with the replacement of ions in the electric double layer, the physical properties of the soil changed significantly, which specifically included the permeability, conductivity, and porosity of the soil. When compared with other cations, the migration of $\mathrm{K}^{+}$was relatively stable, while the migration of $\mathrm{Na}^{+}$was more obvious. The content of $\mathrm{Al}^{3+}$ was relatively lower than that of $\mathrm{Mg}^{2+}$ and $\mathrm{Ca}^{2+}$. The quantity of migrated $\mathrm{Na}^{+}$in the soil was caused by the migration of the original $\mathrm{Na}^{+}$and the $\mathrm{Na}^{+}$that was replaced by multicharged ions. $\mathrm{Na}^{+}$serves as the major ion in the soft clay of Taizhou and plays a leading role in the electro-osmotic drainage process. The role of $\mathrm{Na}^{+}$also explains why the electro-osmosis effect of the T4 $\left(\mathrm{Na}^{+}\right)$group was better than that of the T2 $\left(\mathrm{K}^{+}\right)$ group. In terms of the $\mathrm{T} 4\left(\mathrm{Na}^{+}\right)$group, the electro-osmosis effect of increasing only the $\mathrm{Na}^{+}$content was not as efficient as adding multicharged ions such as $\mathrm{Ca}^{2+}$, which could be explained as follows: the components in the soil interlayer could be found mainly as monovalent ions, and the conductivity and permeability of the soil were not notably improved, which further limited the effect of the electroosmosis treatment. The replacement of $\mathrm{Ca}^{2+}$ and $\mathrm{Mg}^{2+}$ in the soil interlayer increased $\mathrm{Na}^{+}$, which was also associated with the migration of the pore water and that changed the crystal layer structure of the soil. Considering the macrolevel, these findings also explained why T3 $\left(\mathrm{Mg}^{2+}\right)$ and T5 $\left(\mathrm{Ca}^{2+}\right)$ groups presented a better effect of drainage and a higher electroosmotic permeability coefficient than those of the monovalent ion groups and control.

3.3. Theoretical Level. Esrig [18] assumed that the electroosmotic permeability coefficient of the soil had nothing to do with time in the electro-osmotic consolidation theory proposed in 1968. Since then, most of the theoretical equations concerning electro-osmotic consolidation [19-21] have also been proposed according to this assumption. However, Esrig's assumptions did not fully accord with the test results. As illustrated in Figure 7, a smaller rate of drainage, a lower effective voltage, and a smaller electroosmotic permeability coefficient were detected with the electro-osmosis process. Consequently, exploring the method of simulating changes in the electro-osmotic permeability coefficient may serve as the key to further improving the theory of electro-osmosis consolidation. The electro-osmotic method was theoretically investigated according to the inherent link between the macro- and microlevels; thus, a new one-dimensional electro-osmotic consolidation equation was hereby deduced. These expressions are intended to provide a reference for the subsequent promotion and application of the electro-osmotic method.

3.3.1. Basic Assumptions. The following basic assumptions were made to establish a new one-dimensional electro-osmotic consolidation equation that considered variations in the electro-osmotic permeability coefficient. (1) The soil is fully saturated and homogeneous. Decreases in the number of soil particles and the pore water content during consolidation can be neglected. (2) The drainage amount discharged from a unit cell of soil is equal to the decrease in the soil volume. (3) The coefficient of the hydraulic permeability of the soil is assumed to be constant during the consolidation process. (4) The movement of water flow caused by various chemical concentrations and heat can also be neglected. (5) Compressive strains are only allowed in the vertical direction. (6) The flow caused by the electrical gradient can be superimposed with the flow caused by the hydraulic gradient.

\subsubsection{Establishment of the Expression Concerning the Var-} iation in the Electro-Osmotic Permeability Coefficient. The results showed that the drainage rate gradually decreased in the later stage of electro-osmosis and that the electro-osmotic drainage velocity was zero at the undischarged stage. The calculation method of the electro-osmotic permeability coefficient is given in formula (1), and the electro-osmotic permeability coefficient was zero at the end of this experiment. For the purpose of facilitating the practical calculation and simplifying the required parameters, the initial electro-osmotic permeability coefficient and the treatment time of electro-osmosis were hereby applied to fit the linear curve of the variation in the electro-osmotic permeability coefficient to approximate the attenuation law. Figure 11 shows the fitting curve of the electro-osmotic 


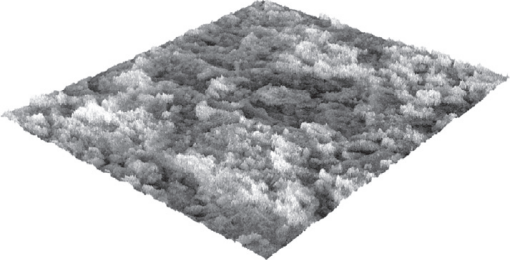

(a)

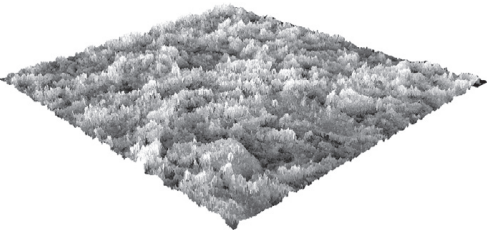

(d)

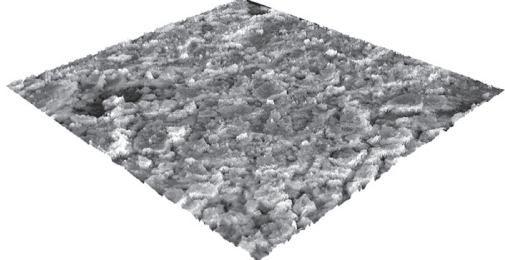

(b)

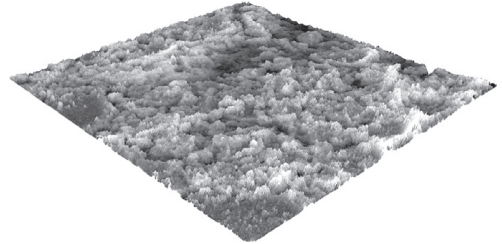

(e)

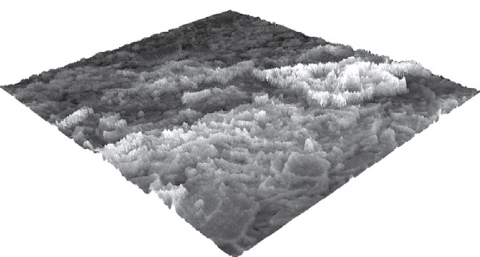

(c)

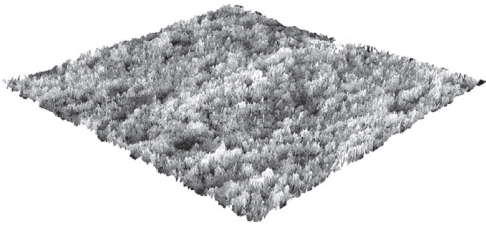

(f)

Figure 9: 3D visualizations of the soil surfaces before and after the electro-osmosis process. (a) Untreated soil. (b) T1 (no solute). (c) T2 (K ${ }^{+}$). (d) $\mathrm{T} 3\left(\mathrm{Mg}^{2+}\right) \cdot\left(\right.$ e). $\mathrm{T} 4\left(\mathrm{Na}^{+}\right)$. (f) $\mathrm{T} 5\left(\mathrm{Ca}^{2+}\right)$.

TABLE 3: Change in soil porosity before and after the electro-osmosis process.

\begin{tabular}{|c|c|c|c|c|}
\hline Test numbers & Particle volume & Pore volume & Total volume & Porosity (\%) \\
\hline Untreated soil & 32530744 & 199831714 & 232362458 & 86.0 \\
\hline $\mathrm{T} 1$ & 48101123 & 184271452 & 232372575 & 79.3 \\
\hline $\mathrm{T} 2$ & 97881269 & 134450251 & 232331520 & 57.87 \\
\hline T3 & 174637233 & 58523292 & 233160525 & 25.1 \\
\hline $\mathrm{T} 4$ & 113542718 & 119604547 & 233147265 & 51.3 \\
\hline T5 & 174357532 & 58740773 & 233098305 & 25.2 \\
\hline
\end{tabular}

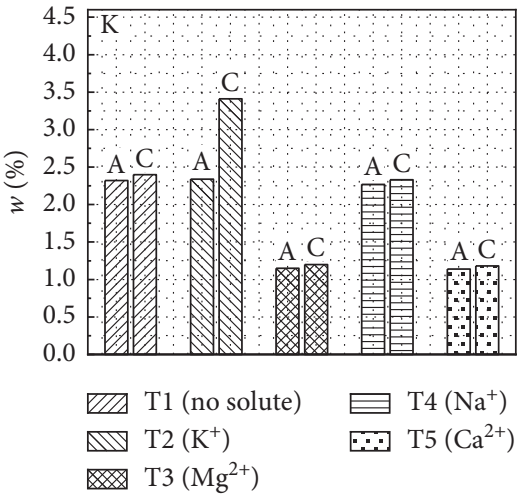

(a)

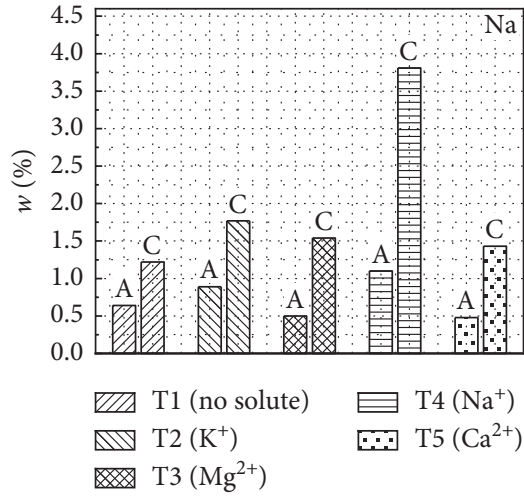

(b)

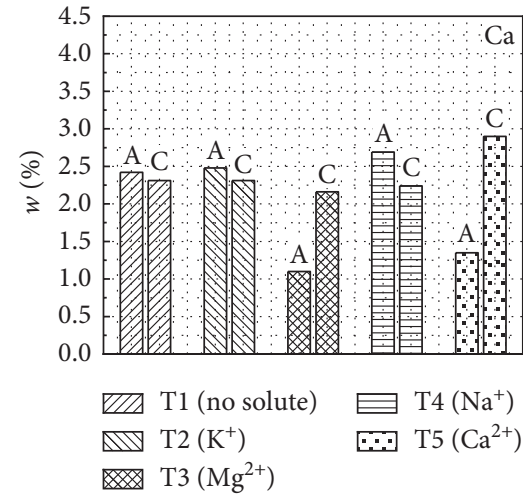

(c)

Figure 10: Continued. 


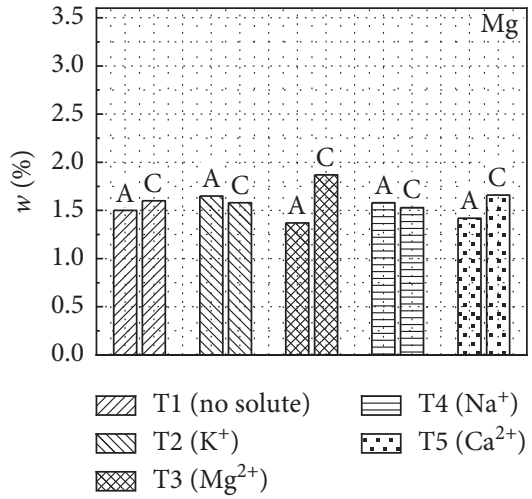

(d)

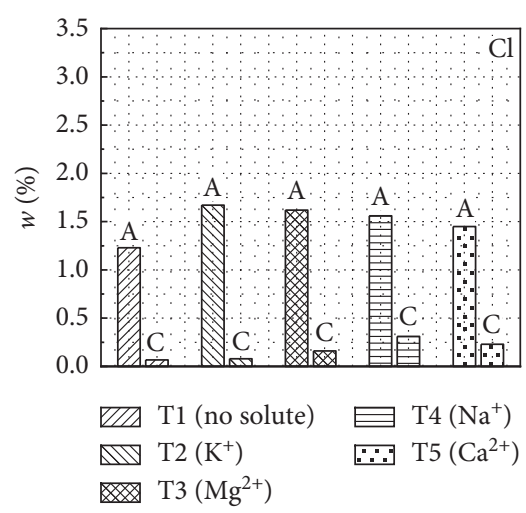

(e)

FIGURE 10: Contents of each element in the soil at the anode and cathode electrodes after the electro-osmosis process. (a) Contents of potassium. (b) Contents of sodium. (c) Contents of calcium. (d) Contents of magnesium. (e) Contents of chlorine.

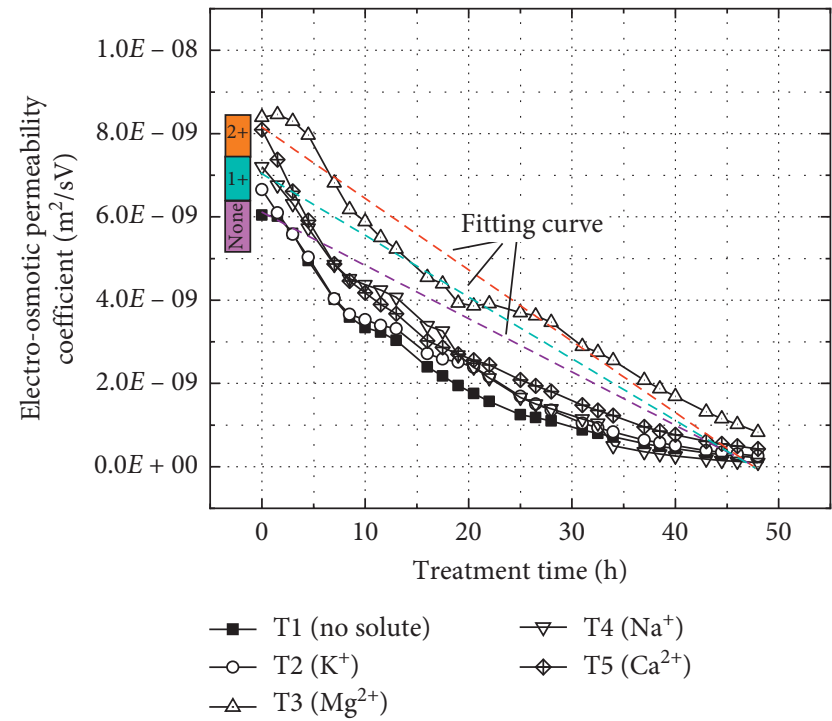

FIGURE 11: Fitted curves of the electro-osmotic permeability coefficient over treatment time.

permeability coefficients with varied valence states. The study showed that the injection of high valence ions in the soil promoted the initial electro-osmotic permeability coefficient, which further improved the drainage efficiency. Based on the concrete data, the electro-osmotic permeability coefficient of divalent ions ranged from $7.5 \times 10^{-9} \mathrm{~m}^{2} / \mathrm{sV}$ to $8.5 \times 10^{-9} \mathrm{~m}^{2} / \mathrm{sV}$, the coefficient of univalent ions ranged from $6.5 \times 10^{-9} \mathrm{~m}^{2} / \mathrm{sV}$ to $7.4 \times 10^{-9} \mathrm{~m}^{2} / \mathrm{sV}$, and the electroosmotic permeability coefficient without a solute treatment was found to be less than $6.4 \times 10^{-9} \mathrm{~m}^{2} / \mathrm{sV}$.

The expression of the electro-osmotic permeability coefficient over time is hereby written as follows on the basis of the characteristics of the fitted curve:

$$
\frac{k_{e}(t)}{k_{e 0}}+\frac{t}{t_{0}}=1
$$

where $k_{e}(t)$ refers to the electro-osmotic permeability coefficient over time, $t_{0}$ is the construction time, and $k_{e 0}$ is the initial electro-osmotic permeability coefficient, which uses the valence of the saline solute as a reference.

Formula (2) is hereby introduced as a general formula for the expression of the electro-osmotic permeability coefficient:

$$
k_{e}(t)=P t+Q
$$

where $P=-\left(k_{e 0} / t_{0}\right)$ and $Q=k_{e 0}$.

\subsubsection{Establishment of the One-Dimensional Electro-Osmosis} Consolidation Equation. The electro-osmotic pore water flow velocity is coupled with the hydraulic gradient flow and electrical gradient flow according to assumption (6):

$$
q_{h}=k_{h} i_{h}+k_{e} i_{e} .
$$

The following expressions can be obtained when assumptions (1) and (2) are combined with Terzaghi's onedimensional electro-osmosis consolidation theory:

$$
\begin{aligned}
& \operatorname{div} q_{h}=m_{v} \frac{\partial u}{\partial t}, \\
& \operatorname{div} q_{h}=\frac{\partial q_{h}}{\partial x}=\frac{k_{h}}{\gamma_{w}} \frac{\partial^{2} u}{\partial x^{2}}+k_{e} \frac{\partial^{2} \varphi}{\partial x^{2}}=m_{v} \frac{\partial u}{\partial t},
\end{aligned}
$$

where $u$ is the excess pore water pressure, $\varphi$ is the effective voltage, $k_{h}$ and $k_{e}$ are the coefficients of the hydraulic permeability and electro-osmosis, respectively, $x$ is the distance to the cathode, $\gamma_{w}$ is the unit weight of water, $t$ is the time, $m_{v}$ is the soil volume compressibility coefficient, and $q_{h}$ is the velocity of pore water.

With reference to Shen's [22] electro-osmotic consolidation equation that considers variations in the effective voltage $(\varphi(x, t)=(M \ln (t)+N)(x / L))$, the correlation coefficients were determined to be $M=-0.25$ and $N=5.2$ with a voltage gradient of $1.0 \mathrm{~V} / \mathrm{cm}$. Combined with the variation in the electro-osmotic permeability coefficient, the product of the electro-osmotic permeability coefficient and effective voltage $(z)$ can be described as follows: 


$$
z(x, t)=(P t+Q)(M \ln (t)+N) \frac{x}{L} .
$$

The variable $\xi$ is introduced such that $\xi(x, t)=$ $u(x, t)+\left(\gamma_{w} / k_{h}\right) z(x, t)$. The following equations can be obtained when formulas (6) and (7) are combined:

$$
\begin{aligned}
\frac{\partial \xi}{\partial t} & =c_{h} \frac{\partial^{2} \xi}{\partial x^{2}}+f(x, t), \\
f(x, t) & =\frac{\gamma_{w}}{k_{h}} \times\left[P M \ln t+P(M+N)+\frac{Q M}{t}\right],
\end{aligned}
$$

where $C_{h}=k_{h} / m_{v} \gamma_{w}$ can be expressed as the horizontal consolidation coefficient.

According to the drainage condition of the experiment, the anode is closed, and the cathode is open; consequently, the boundary conditions can be expressed as follows:

$$
\begin{aligned}
\xi(0, t) & =0, \\
\xi_{x}(L, t) & =0 .
\end{aligned}
$$

Additionally, the initial conditions can be described as follows:

$$
\xi(x, 0)=u(x, 0)+\frac{k_{e} \gamma_{w}}{k_{h}} \varphi(x, 0) .
$$

The eigenfunction method is hereby applied to solve the one-dimensional nonhomogeneous heat conduction equation mentioned above.

Given

$$
\xi(x, t)=\sum_{k=0}^{\infty} T_{k}(t) \sin \left(\frac{(2 k+1) \pi}{2 L} x\right),
$$

the analysis can be written as follows:

$$
\begin{aligned}
u(x, t) & =u_{1}(x, t)+u_{2}(x, t)-\frac{\gamma_{w}}{k_{h}} z(x, t), \\
u_{1}(x, t) & =\sum_{k=0}^{\infty} \frac{8 k_{e 0} N \gamma_{w}(-1)^{k}}{k_{h}(2 k+1)^{2} \pi^{2}} \times \exp \left(-\left(k+\frac{1}{2}\right)^{2} \pi^{2} T_{v}\right) \times \sin \left(\left(k+\frac{1}{2}\right) \times \frac{\pi}{L} x\right), \\
u_{2}(x, t) & =\sum_{k=0}^{\infty}(A+B+C) \times \frac{8(-1)^{k} \gamma_{w}}{k_{h}(2 k+1)^{2} \pi^{2}} \times \exp \left(-\left(k+\frac{1}{2}\right)^{2} \pi^{2} T_{v}\right) \times \sin \left(\left(k+\frac{1}{2}\right) \times \frac{\pi}{L} x\right), \\
A & =\frac{P M}{(k+(1 / 2))^{2}\left(\pi^{2} c_{h} / L^{2}\right)} \exp \left(\left(k+\frac{1}{2}\right)^{2} \frac{\pi^{2} c_{h}}{\left.L^{2} t\right) \times \ln t,}\right. \\
B & =\frac{P(M+N)}{(k+(1 / 2))^{2}\left(\pi^{2} c_{h} / L^{2}\right)}\left[\exp \left(\left(k+\frac{1}{2}\right)^{2} \frac{\pi^{2} c_{h}}{L^{2}} t\right)-1\right], \\
C= & \left(Q M-\frac{P M}{(k+(1 / 2))^{2}\left(\pi^{2} c_{h} / L^{2}\right)}\right) \int_{0}^{t} \exp \frac{\left((k+(1 / 2))^{2}\left(\pi^{2} c_{h} / L^{2}\right) \tau\right)}{\tau} \mathrm{d} \tau, \\
T_{v} & =\frac{c_{h} t}{L^{2}} .
\end{aligned}
$$

In particular, the soil voltage can be constant if $M$ and $N$ are both zero; $P=0$ and $Q=k_{e 0}$. Therefore, formula 14 can be rewritten as follows:

$$
u(x, t)=-\frac{k_{e} \gamma_{w}}{k_{h}} \varphi+u_{1}(x, t) .
$$

Formula (19) is consistent with the expression of the excess pore water pressure in Esrig's one-dimensional electro-osmotic consolidation theory. Therefore, the above equation can be regarded as a special solution for the pore water stress under ideal conditions.

3.3.4. Verification of the Sample. The experiments with $\mathrm{Na}^{+}$ and $\mathrm{Ca}^{2+}$ saline were conducted to verify the rationality of the one-dimensional electro-osmotic consolidation equation that considered variations in the electro-osmotic permeability coefficient. The basic conditions of this experiment were essentially the same as those described above except 
that two micropore water pressure gauges were embedded near the anode to monitor excess pore water pressure over time in that area.

According to the initial experimental conditions of T4 $\left(\mathrm{Na}^{+}\right)$, where $k_{e 0}=6.5 \times 10^{-9} \mathrm{~m}^{2} / \mathrm{sV}$ and $t=48 \mathrm{~h}$, the correlation coefficients were determined to be $P=-3.8 \times 10^{-14}$ and $Q=6.5 \times 10^{-9}$. According to the initial experimental conditions of T5 $\left(\mathrm{Ca}^{2+}\right)$, where $k_{e 0}=8 \times 10^{-9} \mathrm{~m}^{2} / \mathrm{sV}$ and $t=48 \mathrm{~h}$, the correlation coefficients were determined to be $P=-4.6 \times 10^{-14}$ and $Q=8.0 \times 10^{-9}$. Furthermore, the basic soil parameters were demonstrated as follows. The effective voltage coefficients were determined to be $M=-0.25$ and $N=5.27$, the hydraulic permeability $\left(k_{h}\right)$ was $2 \times 10^{-8} \mathrm{~m} / \mathrm{s}$, the horizontal consolidation parameter $\left(c_{h}\right)$ was $8 \times 10^{-8} \mathrm{~m}^{2} / \mathrm{s}$, and $L$ was $0.15 \mathrm{~m}$. These parameters were then substituted into formulas (12) and (19). The theoretical values of the excess pore water pressure considering variations in the electro-osmotic permeability coefficient and Esrig's theory could be hereby obtained. Figure 12 shows the calculated values of the excess pore water pressure considering variations in the electro-osmotic permeability coefficient in $\mathrm{T} 4\left(\mathrm{Na}^{+}\right)$, the calculated values of the excess pore water pressure considering variations in the electro-osmotic permeability coefficient in T5 $\left(\mathrm{Ca}^{2+}\right)$, the measured values of T4 $\left(\mathrm{Na}^{+}\right)$, the measured values of T5 $\left(\mathrm{Ca}^{2+}\right)$, and the calculated values of the excess pore water pressure considering Esrig's theory, where the calculated values of T4 $\left(\mathrm{Na}^{+}\right)$and T5 $\left(\mathrm{Ca}^{2+}\right)$ were the same.

As shown in Figure 12, the excess pore water pressure calculated by Esrig's consolidation equation gradually decreased and tended to be stable. Without considering the change in the electro-osmotic permeability coefficient and soil voltage, Esrig's values could be much larger than the measured values. However, when considering the effective voltage of the soil and the law of the electro-osmotic permeability coefficient, the theoretical value of the excess pore water pressure presented a trend that decreased first and then increased slightly over time. Such phenomena corresponded to the measured value of the T5 $\left(\mathrm{Ca}^{2+}\right)$ group. Moreover, the T4 $\left(\mathrm{Na}^{+}\right)$group exhibited a trend of decreasing first and then becoming stable. Thus, the calculated values mentioned above could be much closer to the measured values than that of Esrig's theory, which proved the rationality of the one-dimensional consolidation equation, which considered variations in the electro-osmotic permeability coefficient, deduced in this paper.

The pore water gradually discharged from the cathode driven by the electromotive force at the early stage of the test, and the excess pore pressure continued to decrease. The rebound trend was related to the attenuation of the electroosmotic permeability coefficient. Then, the pore water flowed to the cathode under the combined effect of the hydraulic gradient and electric gradient at the initial stage. After that, the balance of the pore water flow was broken as the effective voltage and the electro-osmotic permeability coefficient continued to decrease, and a small portion of pore water in the cathode flowed back to the anode under the influence of drainage channels and gravity, which later caused the redistribution of the excess pore water pressure.

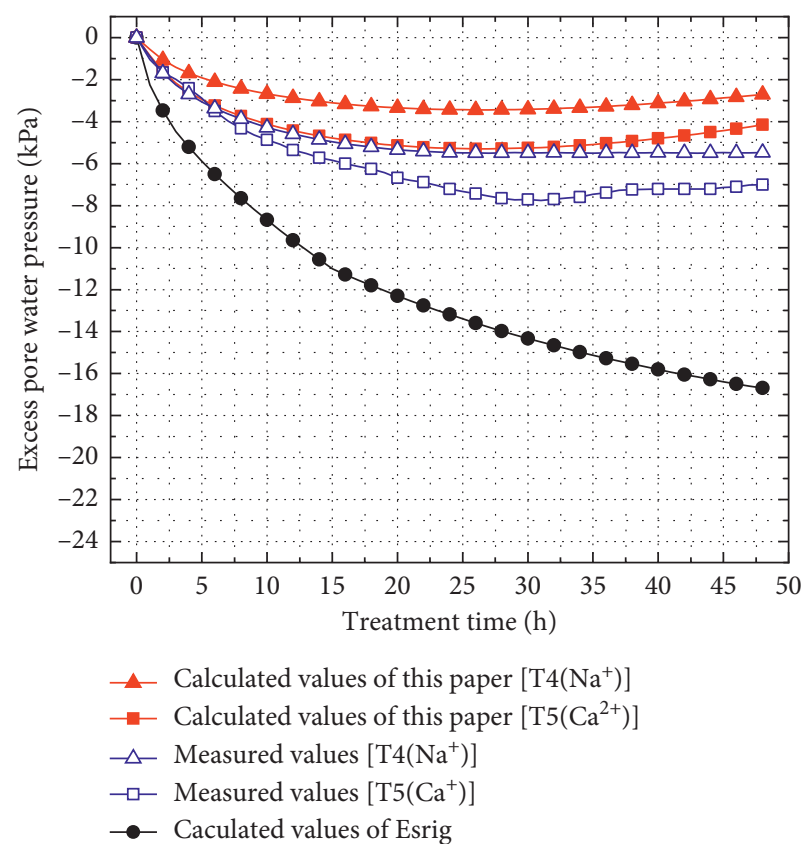

Figure 12: Comparison between the calculated and measured values of excess pore water pressure.

In particular, in the late stage of the experiment, the pore water could not be effectively driven by the hydraulic seepage force, causing the excess pore pressure to gradually stabilize or present a rebound. The abovementioned phenomena all explain why the performance of electro-osmosis is not as good in the late period.

Additionally, temperature also serves as one of the factors that may cause the rebound of excess pore water pressure. During the test process, the soil temperature at the anode increased significantly, which led to the generation of positive excess pore water pressure. In the early stage, the shrinking trend of the fitted curve and the change rule reflected by the measured values share some similarities. Due to the temperature increase and the chemical reactions that occur, certain errors concerning the calculated and measured values were introduced. In subsequent studies, numerical simulation research could be conducted concerning these factors, namely, the temperature field or drainage channels that could be affected by cracks.

\section{Conclusion}

A series of chemical electro-osmosis experiments were conducted on soft clay from Taizhou under five different conditions. The results were analyzed from both the macro and micro and theoretical levels. From the experiments, the following conclusions can be drawn:

(1) The structure of clay lattices was significantly changed through electro-osmosis after the injection of $\mathrm{CaCl}_{2}$ and $\mathrm{MgCl}_{2}$ saline. Moreover, $\mathrm{Na}^{+}$was replaced by multicharged ions, which later served as the key factor affecting both the drainage efficiency and conductivity of the electro-osmotic process. 
However, the electro-osmosis effect of adding $\mathrm{Na}^{+}$ solution alone was not as efficient as adding multicharged ions such as $\mathrm{Ca}^{2+}$.

(2) With the injection of $\mathrm{CaCl}_{2}$ and $\mathrm{MgCl}_{2}$ saline, the soil changed from a flocculent structure to a granular or laminated structure after the electro-osmotic treatment, which leads to the reduction of the soil porosity from $86 \%$ to about $25 \%$. Meanwhile, the colloidal substance generated by $\mathrm{Ca}^{2+}$ and $\mathrm{Mg}^{2+}$ at the cathode could make not only cement the loose soil particles but also fill the pores.

(3) As electro-osmosis progressed, the electro-osmotic permeability coefficient decayed over time. The initial electro-osmotic permeability coefficient could be detected to be relatively high after the injection of $\mathrm{CaCl}_{2}$ and $\mathrm{MgCl}_{2}$ saline. Based on the inherent link between the macro- and microperspectives, a novel one-dimensional electro-osmotic consolidation equation, which considered variations in the electroosmotic permeability coefficient, was deduced. When compared with Esrig's equation, the new equation was more consistent with the measured data. Under the effect of the decreased electro-osmotic permeability coefficient and the increased temperature, the excess pore pressure gradually stabilized, and a small rebound was detected. Such phenomena well explained why electro-osmosis was found to have such poor performance in the late period of the test. These results could provide some references and evidence for the application and improvement of electro-osmotic methods in the treatment of soft clay foundations.

\section{Data Availability}

The data used to support the findings of this study are available from the corresponding author upon request.

\section{Conflicts of Interest}

The authors declare that they have no conflicts of interest related to the publication of this paper.

\section{Acknowledgments}

The authors would like to acknowledge the contribution of Feng Jianting and $\mathrm{Wu}$ Jiawei during the experimental program of the study. This work was supported by the 111 Project of Ministry of Education of the People's Republic of China (grant no. B13024) and the project of research on theory and engineering application of vacuum preloading combined with electro-osmosis method using EKG sponsored by China Railway Construction Group Co., Ltd.

\section{References}

[1] L. J. Wang, S. H. Liu, J. B. Wang, and W. Xu, "Model test for high-water-content soft soil treatment under vacuum preloading in combination with electroosmosis," Journal of Hohai University, vol. 39, no. 6, pp. 671-675, 2011.

[2] P. C. Hu, J. Zhou, X. G. Wen, and X. Y. Cheng, "Laboratory model experiment of electro-osmosis combined with loading and pneumatic fracturing," Journal of Zhejiang University (Engineer Science), vol. 49, no. 8, pp. 1434-1440, 2015.

[3] H. T. Fu, J. wang, and Y. Q. Cai, "Experimental study of combined application of electroosmosis and low-energy dynamic compaction in soft ground reinforcement," Chinese Journal of Rock Mechanics and Engineering, vol. 34, no. 3, pp. 612-620, 2015.

[4] Z. Sun, M. Gao, and X. Yu, "Vacuum preloading combined with electro-osmotic dewatering of dredger fill using electric vertical drains," Drying Technology, vol. 33, no. 7, pp. 847-853, 2015.

[5] S. Laursen, "Laboratory investigation of electroosmosis in bentonites and natural clays," Canadian Geotechnical Journal, vol. 34, no. 5, pp. 664-671, 1997.

[6] S. Ozkan, R. J. Gale, and R. K. Seals, "Electrokinetic stabilization of kaolinite by injection of $\mathrm{Al}$ and $\mathrm{PO}_{4}{ }^{3-}$ ions," Proceedings of the Institution of Civil Engineers-Ground Improvement, vol. 3, no. 4, pp. 135-144, 1999.

[7] G. Lefebvre and F. Burnotte, "Improvements of electroosmotic consolidation of soft clays by minimizing power loss at electrodes," Canadian Geotechnical Journal, vol. 39, no. 2, pp. 399-408, 2011.

[8] F. Burnotte, G. Lefebvre, and G. Grondin, "A case record of electroosmotic consolidation of soft clay with improved soil-electrode contact," Canadian Geotechnical Journal, vol. 41, no. 6, pp. 1038-1053, 2004.

[9] E. Mohamedelhassan and J. Q. Shang, "Electrokinetics-generated pore fluid and ionic transport in an offshore calcareous soil," Canadian Geotechnical Journal, vol. 40, no. 6, pp. 1185-1199, 2003.

[10] C.-Y. Ou, S.-C. Chien, and Y.-G. Wang, "On the enhancement of electroosmotic soil improvement by the injection of saline solutions," Applied Clay Science, vol. 44, no. 1-2, pp. 130-136, 2009.

[11] C. J. F. P. Jones, J. Lamont-Black, and S. Glendinning, "Electrokinetic geosynthetics in hydraulic applications," Geotextiles and Geomembranes, vol. 29, no. 4, pp. 381-390, 2011.

[12] Y. L. Tao, J. Zhou, and X. N. Gong, "Experimental study on function mechanism of electrode materials upon electro-osmotic process," Journal of Zhejiang University, vol. 48, no. 9, pp. 1618-1623, 2014.

[13] Y. Li and X. N. Gong, "Experimental study on effect of soil salinity on electro-osmotic dewatering in soft clay," Chinese Journal of Geotechnical Engineering, vol. 33, no. 8, pp. 1254-1259, 2011.

[14] H. Wu, "Soft soil improvement by electro-osmosis techniques," M. S. thesis, Tsinghua University, Beijing, China, 2015.

[15] P. C. Hu, "Experiment study on the influential factors and improving method of electro-osmotic permeability of soft clay," M. S. thesis, Zhejiang University, Hangzhou, China, 2015.

[16] B. J. Wang, B. Shi, and Y. Cai, "3D visualization and porosity computation of clay soil SEM image by GIS," Rock and Soil Mechanics, vol. 29, no. 1, pp. 251-255, 2008.

[17] J. K. Mitchell and K. Soga, Fundamentals of Soil Behaviour, John Wiley \& Sons, Hoboken, NJ, USA, 3rd edition, 2005. 
[18] M. I. Esrig, "Pore pressures, consolidation, and electrokinetics," Journal of the Soil Mechanics \& Foundations Division, vol. 94, no. 4, pp. 899-922, 1986.

[19] J. Q. Su and W. Zhao, "Theory of two-dimensional electroosmotic consolidation of soils," Rock and Soil Mechanics, vol. 25, no. 1, pp. 125-131, 2004.

[20] M. X. Gong, L. D. Wang, and G. G. Zhan, "1-D electro-osmotic consolidation theory considering variation in effective potential in soft soil," Hydrogeology and Engineering Geology, vol. 42, no. 4, pp. 67-72, 2015.

[21] L. J. Wang, Y. M. Wang, and S. H. Liu, "2D analytical solution of consolidation for vacuum preloading combined with electro-osmosis drainage considering reduction of effective voltage," Chinese Journal of Rock Mechanics and Engineering, vol. 38, no. S1, pp. 3134-3141, 2019.

[22] Y. Shen, "Effects of voltage gradients on electro-osmotic characteristics of Taizhou soft clay," International Journal of Electrochemical Science, vol. 2019, no. 14, pp. 2136-2159, 2019. 